Revista de Economia Política, vol. 28, $n^{\circ} 3$ (111), pp. 454-470, julho-setembro/2008

\title{
Rendimentos crescentes e a distribuição internacional de renda
}

\section{ALEXANDRE DE ZAGOTTIS*}

Increasing returns and the international distribution of income. The existence of increasing returns in high technology industries assigns a path dependent character to the international division of labor. Rich countries, first entrants in these industries, enjoy permanent advantages that prevent, in a free market environment, the development of such industries in middle-income countries. This dynamics allows the former group of countries to experience a higher growth rate of labor productivity than the latter, and, as a result, increases the gap between the workers' standard of living in these countries. It is up to the States of middle-income countries the task of devising development strategies capable of breaking such pattern and improving the international distribution of income.

Keywords: increasing returns; externalities; international division of labor; national strategy.

JEL Classification: D62; F15; F43; O25; O38; O47.

A intensificação do comércio internacional estimulada pela globalização conduz, nos setores de tradables, a um aprofundamento da divisão internacional de trabalho e a uma realocação dos estoques de fatores, outros que trabalho, destinados à produção deste tipo de bem em cada Estado-nação. A estrutura produtiva resultante deste processo condiciona a produtividade da mão-de-obra em cada Estado-nação, que é função da produtividade total de fatores e do estoque de fatores, outros que trabalho, empregado por cada Estado-nação nos setores em que atua, e determina, conseqüentemente, o padrão de vida dos habitantes de cada Estado-nação.

Partindo da premissa sugerida por Arthur (1996) de que os avanços tecno-

* Bacharel em Engenharia de Produção pela Universidade de São Paulo, Master in Business Administration pelo Massachusetts Institute of Technology e Doutor em Economia de Empresas pela Fundação Getulio Vargas. e-mail: azagottis@drogaraia.com.br. Submetido: Abril 2007; Aprovado: Junho 2007. 
lógicos das últimas décadas criaram dois mundos empresariais - um mundo de setores de alta tecnologia, marcado por rendimentos crescentes de escala, e um mundo de setores tradicionais, marcado por rendimentos constantes ou decrescentes de escala —, avanço neste artigo a tese de que: (i) esta separação de dois mundos impõe, sob o livre funcionamento dos mercados, um caráter path-dependent à divisão internacional de trabalho; (ii) o padrão resultante de divisão internacional de trabalho estabelece, sob certas condições, uma tendência de ampliação da diferença de padrão de vida entre os trabalhadores de países ricos e de renda média ao longo do tempo; e (iii) esta dinâmica revela mecanismos específicos de ação do Estado de países de renda média capazes de compensar os problemas de coordenação impostos pela existência de rendimentos crescentes nos setores de alta tecnologia, e que devem fundamentar as estratégias de desenvolvimento destes países para promover uma melhor distribuição internacional de renda.

$\mathrm{Na}$ seção 1, discuto o conceito de estratégia de desenvolvimento. Na seção 2, apresento o trabalho de Arthur (1996) para introduzir a premissa de separação de dois mundos empresariais. $\mathrm{Na}$ seção 3 , demonstro que a premissa sugerida por Arthur (1996) implica a tese apresentada acima. Finalmente, na seção 4, avalio as implicações normativas desta tese para a economia brasileira.

\section{POLÍTICAS PÚBLICAS, INSTITUIÇÕES E A ESTRATÉGIA NACIONAL DE DESENVOLVIMENTO}

A estratégia de desenvolvimento do Estado-nação se define em dois níveis: (i) o das políticas públicas e (ii) o da estrutura institucional. As políticas públicas influenciam os preços relativos de bens e fatores. Modificam, portanto, os principais preços da economia - a taxa de juro, a taxa esperada de lucro, os salários, a taxa de inflação e a taxa de câmbio - e promovem, desta forma, uma realocação de recursos escassos que impacta o bem-estar dos indivíduos. A estrutura institucional, por sua vez, condiciona o impacto das políticas públicas sobre o bem-estar dos indivíduos. Pode, por um lado, tornar mais ou menos custoso o processo dinâmico de realocação de recursos promovido pelas políticas públicas. Pode, por outro lado, regular diretamente a intensidade dos fluxos realocativos de bens e fatores.

Um país que introduz políticas públicas que induzem, através de uma dada variação nos preços relativos de bens e fatores, uma realocação setorial de mãode-obra, observará um impacto distinto destas políticas em função de sua estrutura institucional, que determina os custos de transação dos fluxos realocativos ou regula diretamente a intensidade destes fluxos. Se, neste processo, os setores que absorverem nova mão-de-obra demandarem um tipo de qualificação incompatível com o nível educacional dos trabalhadores, ou se o mercado de trabalho for rígido por impor elevados custos trabalhistas às empresas, esta realocação será mais custosa e os fluxos realocativos terão menor intensidade, ou poderão mesmo nem ocorrer. Ou ainda, se a estrutura institucional regular os fluxos imigratórios, pode 
impedir a importação de mão-de-obra que tenha a qualificação desejada, restringindo, também, o impacto realocativo destas políticas.

Da mesma forma, políticas públicas que promovam o desenvolvimento de indústrias intensivas em conhecimento, através de subsídios fiscais e desvalorizações cambiais, podem ser mais ou menos efetivas dependendo não só do nível de qualificação da mão-de-obra disponível, como no exemplo anterior, mas também das legislações comercial e financeira, que podem impor maiores ou menores custos ao empreendedorismo, principalmente através da lei de falências, e de um arcabouço regulatório do sistema financeiro que mitigue custos de transação relacionados à assimetria informacional entre poupadores e tomadores, e permita assim que se canalize de forma eficiente a poupança disponível para investimentos em inovação. Ou ainda, se a estrutura institucional regular os fluxos internacionais de capital, pode impedir a importação de poupança para investimentos em inovação, restringindo, também, o impacto realocativo destas políticas.

Portanto, enquanto o Estado promove, no primeiro nível de decisão, uma realocação de recursos escassos na economia através de suas políticas públicas que modificam os preços relativos de bens e fatores - condiciona, no segundo nível, o impacto das políticas do primeiro nível através de reformas institucionais que influenciam os custos de transação inerentes à dinâmica deste processo realocativo, ou regulam diretamente a intensidade dos fluxos realocativos. Estes dois níveis, combinados, formam a estratégia de desenvolvimento do Estado-nação.

O desenvolvimento econômico de um Estado-nação, definido por BresserPereira (2007) como o processo de elevação da produtividade da mão-de-obra, se dá não só pelo progresso técnico e acumulação de fatores outros que trabalho em um dado setor, mas também pela realocação de mão-de-obra e demais fatores de setores com menor para setores com maior produtividade de mão-de-obra. Estes setores apresentam maior produtividade total de fatores e/ou são mais intensivos em fatores outros que trabalho. Assim, o desenvolvimento econômico de um Estado-nação pode se dar pela modificação do seu papel na divisão internacional de trabalho, processo capaz de elevar a produtividade da mão-de-obra e o padrão de vida dos trabalhadores.

Este processo, contudo, não ocorre de maneira autônoma. Como aponta Hoff (2000), a teoria moderna do desenvolvimento relaciona uma série de problemas de coordenação que impedem que a mão invisível do mercado estimule este processo realocativo. Se o desenvolvimento econômico pode ser impulsionado por um processo realocativo de mão-de-obra e demais fatores de setores com menor para setores com maior produtividade de mão-de-obra, e se este processo, por vezes, precisa ser catalisado pelo Estado, então, do ponto de vista normativo, a estratégia nacional de desenvolvimento deve ser construída de forma a (i) definir políticas públicas que condicionem os preços relativos de bens e fatores de maneira a induzir um processo realocativo de trabalho e demais fatores de produção de setores de baixa para setores de alta produtividade de mão-de-obra, ou para setores que viabilizem elevadas taxas de crescimento à produtividade da mão-de-obra; e (ii) 
estabelecer uma estrutura institucional que torne pouco custoso o processo realocativo de trabalho e demais fatores de produção entre estes setores.

\section{RENDIMENTOS CRESCENTES E OS DOIS MUNDOS EMPRESARIAIS}

Em seu clássico trabalho Increasing Returns and the Two Worlds of Business, Arthur (1996) argumenta que as inovações tecnológicas desenvolvidas a partir das últimas décadas do século passado criaram dois mundos distintos, que coexistem na economia contemporânea: um mundo marcado por rendimentos constantes ou decrescentes de escala, como o descrito pelo modelo neoclássico, refletido em indústrias como as de processamento ou produção de commodities, mais facilmente analisáveis através da premissa de competição perfeita, e outro mundo marcado por rendimentos crescentes de escala, no qual o primeiro entrante goza de vantagens permanentes, não analisáveis através do paradigma da competição perfeita, refletido especialmente nas indústrias de alta tecnologia, intensivas em conhecimento. No mundo de rendimentos constantes ou decrescentes, empresas que têm vantagens competitivas em seus mercados avançam até que, inevitavelmente, esbarram em limitações que possibilitam que um equilíbrio previsível de preços e market share seja atingido. Já no mundo de rendimentos crescentes, empresas que saem na frente tendem a ampliar suas vantagens e realizar um lock-in em seus mercados, enquanto aquelas que saem atrás tendem a ficar cada vez mais distanciadas das líderes. Os rendimentos crescentes não geram um equilíbrio previsível, mas instabilidade, path dependence, e múltiplos equilíbrios. Diversos produtos podem sair vencedores em um mesmo mercado, dependendo do contexto histórico sob o qual o mercado se desenvolve. Exemplos típicos de setores de alta tecnologia, intensivos em conhecimento, marcados por rendimentos crescentes, são o aeroespacial, o farmacêutico, o de biotecnologia, o de telecomunicações, e o de software e hardware de computadores. Arthur (1996) aponta três mecanismos, derivados de externalidades, que geram rendimentos crescentes neste tipo de indústria: elevados custos fixos relacionados a pesquisa e desenvolvimento ( $P \& D)$, efeitos de rede e curvas de aprendizado dos consumidores. Explico, a seguir, estes mecanismos:

(i) Elevados custos fixos, relacionados a P\&D de novas tecnologias, fazem com que o custo médio de um produto seja superior a seu custo marginal, impondo, como sugere Romer (1986, 1990), rendimentos crescentes de escala em relação ao capital e ao trabalho, e competição imperfeita. Os rendimentos crescentes decorrem, neste caso, da natureza não-rival do conhecimento. Uma vez criado, pode ser reutilizado sem custo marginal. Embora existam também investimentos em $P \& D$ que impõem rendimentos crescentes ao capital e ao trabalho na produção de alguns setores tradicionais, estes efeitos tendem a ser mitigados por rendimentos decrescentes na criação de conhecimento. Inovações em setores tradicionais tendem a ser focadas em processos e não em produtos. Implicam, geralmente, produzir mais e melhor do mesmo. Isto faz com que predomine na criação de conhecimento nestes setores uma externalidade negativa, caracterizada por Romer (1996) 
como business-stealing effect, pela qual a introdução de uma tecnologia superior torna as tecnologias existentes menos atrativas. Neste contexto, a duplicação do estoque de conhecimento menos do que dobra a criação de novo conhecimento, e estes rendimentos decrescentes na criação de conhecimento mitigam os rendimentos crescentes na produção em setores tradicionais, e, conseqüentemente, seu impacto sobre a taxa de crescimento da produtividade total de fatores nestes setores. Já a criação de conhecimento em setores de alta tecnologia tende a ser marcada por rendimentos crescentes. Inovações em setores de alta tecnologia tendem a criar novas necessidades e novos mercados, estando menos sujeitas a externalidades negativas. Ao contrário, tendem a ser influenciadas por uma externalidade positiva caracterizada por Romer (1996) como efeito P\&D, pelo qual a produção científica de um pesquisador amplia a produtividade da produção científica de outros pesquisadores. Neste contexto, a duplicação do estoque de conhecimento mais do que dobra a criação de novo conhecimento, e estes rendimentos crescentes na criação de conhecimento intensificam os rendimentos crescentes na produção em setores de alta tecnologia, e, conseqüentemente, seu impacto sobre a taxa de crescimento da produtividade total de fatores nestes setores.

(ii) Efeitos de rede, derivados da intercambiabilidade de determinados produtos de alta tecnologia, ou da existência de ecologias de serviços, tecnologias e produtos que se complementem uns aos outros, fazem com que a ampliação da base de usuários de determinado produto eleve os benefícios por ele proporcionado a todos os seus usuários, tanto por permitir maior intercâmbio entre estes usuários, quanto por criar incentivos econômicos para o desenvolvimento de serviços, produtos e tecnologias voltados à complementação do produto original, enriquecendo a ecologia de serviços, produtos e tecnologias, e possibilitando uma posição de lock-in para produtos que primeiro estabelecem uma massa crítica de usuários em seu mercado.

(iii) Curvas de aprendizado da base de consumidores de produtos de alta tecnologia, normalmente difíceis de se usar, não só elevam o bem-estar obtido por um indivíduo à medida em que usufrui de mais unidades do produto, mas aumentam sobremaneira o custo incorrido por um consumidor para trocar de produto ou tecnologia, e conferem poderes monopolísticos ao líder do mercado.

\section{RENDIMENTOS CRESCENTES E A ESTRATÉGIA NACIONAL}

Por focar sua análise nos impactos de rendimentos crescentes na organização industrial e na estratégia corporativa, Arthur (1996) examina apenas um caso particular de um fenômeno geral: o caso em que as externalidades geradoras de rendimentos crescentes são internalizadas no nível da firma. Contudo, elas podem, de maneira mais geral, apresentar diversos níveis de transbordamento e impactar, de forma decisiva, a trajetória de desenvolvimento dos Estados-nação. Em uma dimensão, estas externalidades podem apresentar diferentes escopos de apropriação, podendo ser internalizadas no nível de uma firma, de um setor econômico, ou de 
um grupo de setores econômicos, dependendo de sua natureza. Em outra dimensão, podem apresentar diferentes alcances geográficos, podendo ser internalizadas em uma região geográfica ou transbordar para outras regiões, dependendo da existência de custos de transação que restrinjam seu alcance geográfico. Para cada tipo de externalidade geradora de rendimentos crescentes discutida na seção 2 há as seguintes possibilidades de transbordamento:

(i) Elevados custos fixos, relacionados a P\&D de novas tecnologias, geram, conforme a discussão da seção 2 , rendimentos crescentes catalisados pela natureza não-rival do conhecimento criado no processo de $\mathrm{P} \& \mathrm{D}$, que permite sua reutilização sem custo marginal. Mas Romer $(1986,1990)$ aponta que, embora não-rival, o conhecimento pode apresentar diversos níveis de exclusividade, que implicam diferentes escopos de apropriação. Em um extremo, pode ser totalmente exclusivo, se for protegido por uma lei de patentes, como as fórmulas de novas drogas, ou se puder ser embutido em um bem exclusivo, como um manual de operações confidencial. Em outro extremo, pode ser completamente não-exclusivo, por exemplo, quando publicado em revistas científicas. Portanto, as externalidades produzidas pelos investimentos em $\mathrm{P} \& \mathrm{D}$, geradoras de rendimentos crescentes, podem variar quanto ao seu escopo de apropriação. Se o conhecimento produzido for exclusivo, pode ser internalizado no nível da firma. Se for não-exclusivo, mas especializado, pode ser internalizado no nível de um setor econômico, para o qual aquele conhecimento tem relevância. Se for não-exclusivo e não-especializado, pode ser internalizado em um nível intersetorial, por um grupo de setores econômicos para os quais aquele conhecimento tem relevância. As externalidades catalisadas pela criação de conhecimento realizada nas atividades de P\&D podem também apresentar transbordamento geográfico variável. Embora o conhecimento tenha natureza não-rival, o que permitiria seu uso sem custo marginal por uma firma, setor, ou grupo de setores em qualquer região geográfica, a sua utilização efetiva na produção demanda, como aponta Romer $(1986,1990)$, capital humano, que tem caráter rival e exclusivo. A acumulação de capital humano reflete o processo de qualificação da mão-de-obra, que a capacita para compreender e utilizar o conhecimento de maneira produtiva. Conseqüentemente, as externalidades geradas pelos investimentos em P\&D, derivadas do caráter não-rival do conhecimento, têm alcance geográfico limitado, porque estes investimentos tornam-se efetivos apenas quando combinados a um tipo de capital humano adequado, de caráter rival e exclusivo, embutido em trabalhadores especializados, capazes de compreender e utilizar o novo conhecimento. A distribuição geográfica destes trabalhadores não é uniforme. Estes trabalhadores concentram-se, geralmente, em pólos tecnológicos especializados. E custos de transação relacionados à mobilidade internacional de pessoas tornam o capital humano um fator de produção com pouca mobilidade geográfica, o que limita o transbordamento geográfico das externalidades geradoras de rendimentos crescentes criadas por investimentos em P\&D.

(ii) Efeitos de rede, derivados da intercambiabilidade de determinados produtos de alta tecnologia, podem apresentar, também, diferentes escopos de apropriação. Quando a intercambiabilidade destes produtos depender de determinado 
padrão tecnológico proprietário de uma firma, como arquivos eletrônicos intercambiáveis produzidos por determinados softwares proprietários de computador, as externalidades de rede são internalizadas no nível desta firma. Quando depender de um padrão tecnológico aberto, específico a um setor, como os arquivos eletrônicos de fotografia digital, as externalidades serão internalizadas no nível de um setor econômico. Quando depender de um padrão tecnológico aberto, de escopo intersetorial, como o protocolo de comunicação que norteia a internet, as externalidades serão internalizados no nível de um conjunto de setores econômicos. Já o transbordamento geográfico destas externalidades depende dos custos de transação relacionados à natureza do produto a ser intercambiado. Produtos digitais, intercambiáveis por redes de computadores, apresentam efeitos de rede com alcance geográfico ilimitado, pois usuários localizados em países distantes podem intercambiar produtos com pouco custo. Mas produtos físicos, intercambiáveis por meios de transporte tradicionais, apresentam efeitos de rede com alcance geográfico limitado, restrito pelo custo de transporte entre diferentes usuários. Mas, ao contrário das externalidades de P\&D, que atuam do lado da oferta, as externalidades de rede derivadas de intercambiabilidade de produtos atuam do lado da demanda. Por isso, mesmo que o alcance geográfico destas externalidades seja limitado, elas não proporcionam, em setores de tradables, vantagem competitiva permanente à produção realizada em uma dada região. Empresas de quaisquer regiões podem se beneficiar destes efeitos de rede, produzindo em suas regiões de origem e exportando seus produtos para as regiões em que exista demanda.

Da mesma forma, os efeitos de rede derivados da existência de ecologias de serviços, tecnologias e produtos que se complementem uns aos outros podem apresentar diferentes escopos de apropriação. Quando estas ecologias se sustentam sobre determinado padrão tecnológico proprietário de uma firma, como a ecologia de serviços, produtos e tecnologias desenvolvida para o padrão de um sistema operacional de microcomputador proprietário de uma firma, as externalidades de rede são internalizadas no nível desta firma. Quando estas ecologias se sustentam sobre um padrão tecnológico aberto, específico a um setor, como a ecologia de serviços, produtos e tecnologias desenvolvida para o padrão de um sistema operacional de microcomputador de arquitetura aberta, ${ }^{1}$ as externalidades de rede são internalizadas no nível de um setor econômico. Quando estas ecologias se sustentam sobre um padrão tecnológico aberto, de escopo intersetorial, como a ecologia de serviços, produtos e tecnologias desenvolvidas para o padrão da internet, as externalidades serão internalizados no nível de um conjunto de setores econômicos. Já o transbordamento geográfico destas externalidades depende dos custos de transação relacionados à interação dos elementos desta ecologia. Um produto tradable inserido em determinada ecologia de serviços, produtos e tecno-

\footnotetext{
${ }^{1}$ Enquanto o Windows, fabricado pela Microsoft, é um exemplo de sistema operacional de microcomputador proprietário de uma firma, o Linux é um exemplo de sistema operacional de arquitetura aberta.
} 
logias apresentará efeitos de rede de alcance geográfico limitado quando os outros elementos de sua ecologia tiverem caráter non-tradable, por conta dos custos de transação relacionados à interação entre eles e o produto tradable. E quando estes elementos non-tradables estiverem do lado da oferta, configurando insumos de produção, conferirão vantagem competitiva permanente, derivada de rendimentos crescentes gerados por efeitos de rede na produção, à firma, setor ou grupo de setores que produzirem o produto em questão na mesma região geográfica em que se encontram estes elementos non-tradables. Caso o produto em questão seja tradable, será produzido com vantagem competitiva na região em que se produzem os insumos non-tradables, internalizando os efeitos de rede, e exportado para outras regiões geográficas.

(iii) Curvas de aprendizado da base de consumidores de produtos de alta tecnologia também podem apresentar diferentes escopos de apropriação. Se o design do produto, que determina a forma de sua utilização, for proprietário de uma firma, como ocorre, por exemplo, com um software de computador, as externalidades da curva de aprendizado serão internalizadas no nível da firma. Se este design for comum a todo o setor econômico, como ocorre, por exemplo, com um computador pessoal, as externalidades serão internalizadas no nível do setor. Por fim, se este design for comum a um grupo de setores, como os websites de empresas, formatados para a World Wide Web, as externalidades serão internalizadas no nível do grupo de setores. Estas externalidades encontram-se do lado da demanda. Assim, em setores de tradables, mesmo que tenham alcance geográfico limitado, podem ser internalizadas por empresas localizadas em quaisquer regiões, que exportam seus produtos para as regiões em que exista demanda.

Estes diferentes níveis de transbordamento de externalidades geradoras de rendimentos crescentes têm influência decisiva no padrão de divisão internacional de trabalho imposto pela globalização em setores de tradables. Quando os rendimentos crescentes derivam de externalidades de alcance geográfico limitado, a globalização força a concentração da produção mundial em regiões sujeitas ao transbordamento destas externalidades, desde que estas atuem do lado da oferta. Quando as externalidades atuam do lado da demanda, mesmo que tenham alcance geográfico limitado, não geram vantagem competitiva a firmas, setores ou grupos de setores de regiões específicas, pois podem ser apropriadas por firmas, setores ou grupos de setores de quaisquer regiões, capazes de exportar seus produtos para as regiões em que exista concentração de demanda. Portanto, os rendimentos crescentes conferem vantagem competitiva permanente a um país em setores de tradables quando derivam de externalidades que (i) atuam do lado da oferta, e (ii) têm alcance geográfico limitado.

Estas conclusões têm implicações normativas importantes para o desenho de estratégias de desenvolvimento de países de renda média. Sugerem que a intervenção do Estado deve se dar de maneira seletiva, incentivando atividades marcadas por externalidades geradoras de rendimentos crescentes derivadas (i) de investimentos em P\&D e (ii) de efeitos de rede catalisados por ecologias de serviços, produtos, e tecnologias que configurem insumos non-tradables para a produção 
de um produto tradable. Estas externalidades atuam, geralmente, do lado da oferta e têm, freqüentemente, alcance geográfico limitado. Conferem assim vantagem competitiva permanente aos produtores de determinadas regiões, impactando de maneira decisiva a divisão internacional de trabalho, e, conseqüentemente, a divisão internacional de renda.

Estas externalidades agem, por exemplo, em pólos tecnológicos, como os de $\mathrm{Si}$ licon Valley e Boston, nos EUA, que concentram, em uma mesma região geográfica, capital humano especializado, empresas de alta tecnologia, que empregam o capital humano e investem pesadamente em P\&D, universidades, que formam capital humano e também investem pesadamente em P\&D, e empresas especializadas de infraestrutura, que oferecem insumos non-tradables específicos para os trabalhadores, empresas, universidades e outras empresas de infra-estrutura que atuam na região. No Brasil, um exemplo deste tipo de pólo é o de São José dos Campos, no Estado de São Paulo. Nascido do Centro Técnico Aeroespacial (CTA), na década de 1950, sob comando da Aeronáutica, este pólo deu origem ao Instituto Tecnológico de Aeronáutica (ITA), que, ainda na década de 1950, formava engenheiros aeronáuticos. Deu origem, também, em 1969, à Embraer, então uma empresa estatal focada na indústria aeronáutica. Ao contrário dos pólos tecnológicos norte-americanos, nos quais predominam investimentos privados, o pólo de São José dos Campos nasceu de investimentos públicos, e deu origem a uma empresa estatal pouco eficiente, que chegou à década de 1990 em situação financeira precária. Com sua privatização, em 1994, a Embraer se recuperou e passou a ser, em poucos anos, o principal exemplo de empresa brasileira protagonista no mercado internacional em um setor de alta tecnologia, marcado por rendimentos crescentes, como o aeronáutico. Sua competitividade no mercado internacional fundamenta-se não só em uma gestão profissional, voltada ao lucro, introduzida pelo capital privado, mas também em externalidades geradoras de rendimentos crescentes, que atuam do lado da oferta, de alcance geográfico limitado, concentradas no pólo tecnológico de São José dos Campos, fomentadas pelo investimento público das décadas anteriores.

A Tabela 1 ilustra todas estas possibilidades de transbordamento das externalidades geradoras de rendimentos crescentes que atuam do lado da oferta, combinando o escopo de apropriação, em uma dimensão, com o alcance geográfico, em outra dimensão, destas externalidades:

Tabela 1: Níveis de Transbordamento das Externalidades Geradoras de Rendimentos Crescentes que Atuam do Lado da Oferta

Escopo de Apropriação

\begin{tabular}{|l|l|ccc|}
\cline { 2 - 5 } & & Firma & Setorial & Intersetorial \\
\cline { 2 - 5 } $\begin{array}{l}\text { Alcance } \\
\text { Geográfico }\end{array}$ & Limitado & (i) & (iii) & (v) \\
\cline { 2 - 5 } & Ilimitado & (ii) & (iv) & (vi) \\
\cline { 2 - 5 }
\end{tabular}

Analiso, a seguir, as implicações de cada uma das possibilidades representadas de maneira esquemática na Tabela 1. A discussão abaixo trata sempre de setores 
de tradables sujeitos a externalidades geradoras de rendimentos crescentes que atuam do lado da oferta, pois são estas que influenciam o padrão de divisão internacional de trabalho e, conseqüentemente, a distribuição internacional de renda.

i. Quando eventuais externalidades, que geram rendimentos crescentes, são internalizadas no nível de uma firma, em uma dada região, a firma que for a primeira entrante no setor gozará de vantagens permanentes no mercado global. Neste caso, estas vantagens existirão apenas na produção que esta firma realizar em uma região específica, na qual se concentram as externalidades. Novas plataformas produtivas desta mesma firma, em outras regiões, não gozarão dos mesmos benefícios, porque custos de transação limitam o alcance geográfico das externalidades. Plataformas produtivas de outras firmas, na mesma região, ou em outras regiões, também não gozarão dos mesmos benefícios, pois estes são exclusivos à firma. Neste cenário, a apropriação das externalidades pela firma gera competição imperfeita, e possibilita que esta firma goze de lucros monopolísticos. A elevação da produtividade total de fatores que os rendimentos crescentes produzem, neste caso, aumenta os lucros apropriados pelo empresário, e, se os rendimentos crescentes derivarem de insumos especializados, e a oferta destes insumos for inelástica em algum grau, o que normalmente ocorre com insumos non-tradables, aumenta os lucros dos produtores de insumos, quando estes forem firmas, ou aumenta os salários reais, quando o insumo for capital humano. Ainda, quando estes insumos forem non-tradables, como geralmente é o capital humano, todos os benefícios gerados pela elevação da produtividade total de fatores serão apropriados na região em que o produto for produzido.

ii. Quando eventuais externalidades, que geram rendimentos crescentes, são internalizadas no nível de uma firma, em todas as regiões em que atua, a firma que for a primeira entrante no setor gozará de vantagens permanentes no mercado global. Neste caso, estas vantagens existirão na produção que esta firma realizar em quaisquer regiões geográficas. Novas plataformas produtivas desta mesma firma, em outras regiões, gozarão dos mesmos benefícios, porque não há custos de transação que limitem o alcance geográfico das externalidades. Plataformas produtivas de outras firmas, na mesma região, ou em outras regiões, não gozarão destes benefícios, pois são exclusivos à firma. Neste cenário também há competição imperfeita, e esta firma se apropria de lucros monopolísticos. A elevação da produtividade total de fatores que os rendimentos crescentes produzem, neste caso, aumenta os lucros apropriados pelo empresário, e, se estes rendimentos crescentes derivarem de insumos especializados, e a oferta destes insumos for inelástica em algum grau, aumenta os lucros dos produtores de insumos, quando estes forem firmas, ou aumenta os salários reais, quando o insumo for capital humano, em todas as regiões em que a firma empreender uma atividade produtiva.

iii. Quando eventuais externalidades, que geram rendimentos crescentes, são externas à firma, mas internas a um setor econômico, em uma dada região, o 
país que for o primeiro entrante no setor gozará de vantagens permanentes no mercado global. Neste caso, estas vantagens serão compartilhadas por todas as firmas do setor em uma dada região, na qual se concentram as externalidades. Novas plataformas produtivas destas mesmas firmas, em outras regiões, não gozarão dos mesmos benefícios, porque custos de transação limitam o alcance geográfico das externalidades. Neste cenário, desde que exista mobilidade internacional e intersetorial de capital que crie uma oferta elástica de capital no setor neste país, a competição entre as firmas que atuam no setor, nesta região, conduzirá suas taxas de lucro a níveis normais, que oferecem um retorno ao capital investido coerente com o de outros setores e países. A elevação da produtividade total de fatores que os rendimentos crescentes produzem, neste caso, gera um aumento dos salários reais dos trabalhadores que atuam no setor e região em questão, desde que a oferta de mão-de-obra deste setor, nesta região, seja inelástica em algum grau, o que ocorre normalmente por conta de custos de transação associados à mobilidade geográfica e intersetorial de trabalhadores.

iv. Quando eventuais externalidades, que geram rendimentos crescentes, são externas à firma, mas internas a um setor econômico, em quaisquer regiões, conduzirão a um cenário competitivo entre todas as firmas do setor, em todas as regiões, porque as externalidades serão compartilhadas por todas as firmas do setor, em todas as regiões. Desde que exista mobilidade internacional e intersetorial de capital que crie uma oferta elástica de capital no setor, em todos os países, a competição entre as firmas que atuam neste setor, em qualquer região, conduzirá suas taxas de lucro a níveis normais, que oferecem um retorno ao capital investido coerente com o de outros setores. A elevação da produtividade total de fatores que os rendimentos crescentes produzem, neste caso, gera um aumento dos salários reais dos trabalhadores que atuam neste setor, em todas as regiões, desde que a oferta de mão-de-obra deste setor seja inelástica em algum grau, o que ocorre normalmente por conta de custos de transação associados à mobilidade intersetorial de trabalhadores.

v. Quando eventuais externalidades, que geram rendimentos crescentes, são externas à firma, externas ao setor econômico, mas internas a um conjunto de setores econômicos, em uma dada região, o país que for o primeiro entrante em qualquer setor deste conjunto gozará de vantagens permanentes em todos os setores deste conjunto no mercado global. Este tipo de vantagem competitiva de um país é particularmente relevante por sua abrangência. Pode se estender, inclusive, a setores que não foram ainda inventados, permitindo uma situação de lock-in, no futuro, de mercados ainda não criados, e que surgirão como resultado de inovações tecnológicas ou mercadológicas, mesmo que estas tenham origem em outros países. Isso ocorrerá desde que estes novos setores estejam sujeitos ao transbordamento de externalidades geradoras de rendimentos crescentes, de caráter intersetorial, que tenham alcance geográfico limitado e que atuem do lado da oferta. Neste caso, as vantagens serão compartilhadas 
por todas as firmas, de todos os setores deste conjunto, em uma dada região, na qual se concentram as externalidades. Novas plataformas produtivas destas mesmas firmas, em outras regiões, não gozarão dos mesmos benefícios, porque custos de transação limitam o alcance geográfico das externalidades. Neste cenário, desde que exista mobilidade internacional e intersetorial de capital que crie uma oferta elástica de capital nestes setores, neste país, a competição entre as firmas que atuam nestes setores, e nesta região, conduzirá suas taxas de lucro a níveis normais, que oferecem um retorno ao capital investido coerente com o de outros setores e países. A elevação da produtividade total de fatores que os rendimentos crescentes produzem, neste caso, gera um aumento dos salários reais dos trabalhadores que atuam nos setores e região em questão, desde que a oferta de mão-de-obra destes setores, nesta região, seja inelástica em algum grau, o que ocorre normalmente por conta de custos de transação associados à mobilidade geográfica e intersetorial de trabalhadores.

vi. Quando eventuais externalidades, que geram rendimentos crescentes, são externas à firma, externos ao setor econômico, mas internas a um conjunto de setores econômicos, em todas as regiões, as vantagens serão compartilhadas por todas as firmas, de todos os setores deste conjunto, em todas as regiões. Neste cenário, desde que exista mobilidade internacional e intersetorial de capital que crie uma oferta elástica de capital nestes setores, a competição entre as firmas que atuam nestes setores, em quaisquer regiões, conduzirá suas taxas de lucro a níveis normais, que oferecem um retorno ao capital investido coerente com o de outros setores. A elevação da produtividade total de fatores que os rendimentos crescentes produzem, neste caso, gera um aumento dos salários reais dos trabalhadores que atuam nestes setores em qualquer região, desde que a oferta de mão-de-obra destes setores seja inelástica em algum grau, o que ocorre normalmente por conta de custos de transação associados à mobilidade intersetorial de trabalhadores.

Os seis cenários distintos sumarizados neste modelo esquemático podem ainda se combinar, de forma a contemplar a existência de apropriação parcial destas externalidades por parte de firmas, setores ou regiões. A estrutura analítica proposta acima sugere que um país que seja o primeiro entrante em determinado tipo de atividade econômica gozará de vantagens permanentes nos cenários (i), (iii), e (v), nos quais os transbordamentos têm alcance geográfico limitado, concentrado do lado da oferta. No cenário (i), os benefícios gerados pelos rendimentos crescentes são apropriados em parte pelos empresários, na forma de maiores lucros, e em parte por trabalhadores, na forma de maiores salários reais. Nos cenários (iii) e (v), os benefícios gerados pelos rendimentos crescentes são apropriados pelos trabalhadores, na forma de maiores salários reais. Quando o alcance geográfico das externalidades não for limitado, como ocorre nos cenários (ii), (iv) e (vi), os rendimentos crescentes não oferecem vantagem competitiva a países específicos, mesmo que as externalidades atuem do lado da oferta, e não estimulam, assim, diferenças de padrão de vida entre países distintos. 
Portanto, as vantagens permanentes do primeiro entrante não se dão, necessariamente, no nível da firma, como sugere Arthur (1996). Podem se dar em setores de tradables, no nível de um grupo de firmas, em um mesmo setor ou em setores distintos, localizadas em determinadas regiões, quando as externalidades atuam do lado da oferta, têm escopo mais amplo de apropriação e alcance geográfico limitado. As externalidades geradoras de rendimentos crescentes que atuam do lado da oferta impõem, assim, um caráter path dependent à divisão internacional do trabalho, porque conferem vantagem competitiva permanente e lock-in a firmas ou grupos de firmas de determinados países, primeiros entrantes em seus mercados. As vantagens permanentes destes países podem se estender, inclusive, a mercados paralelos, existentes ou ainda a serem criados, sujeitos a externalidades geradoras de rendimentos crescentes que atuem do lado da oferta e apresentem transbordamento intersetorial de alcance geográfico limitado. Há um exemplo muito comum e relevante deste tipo de situação: um país que conte com uma força de trabalho qualificada e eclética, apta a aprender e utilizar produtivamente inovações derivadas de P\&D ao redor do mundo, goza de externalidades geradoras de rendimentos crescentes que atuam do lado da oferta, de caráter intersetorial e alcance geográfico limitado, e que se estende a setores ainda nem criados. Esta força de trabalho constitui, portanto, um importante ativo nacional, capaz de conferir vantagem permanente e lock-in ao país em novos setores, intensivos em $P \& D$, que, à medida que sejam inventados, podem passar a representar uma parcela cada vez maior da economia mundial.

A diferenciação entre dois mundos - o tradicional, marcado por rendimentos decrescentes, e o de alta tecnologia, caracterizado por rendimentos crescentes - realizada por Arthur (1996), e generalizada aqui para diferentes níveis de transbordamento das externalidades geradoras de rendimentos crescentes, tem implicações muito importantes para as trajetórias de desenvolvimento dos Estadonação. A existência de rendimentos crescentes em um dado setor acelera o ritmo de crescimento da produtividade total de fatores, e, conseqüentemente, viabiliza uma trajetória de crescimento mais favorável, em que o padrão de vida dos trabalhadores alocados a este setor melhora mais rapidamente do que o de trabalhadores alocados a setores marcados por rendimentos constantes ou decrescentes. $\mathrm{E}$ estas dinâmicas distintas impedem a convergência das trajetórias de desenvolvimento dos países ricos e de renda média, porque a globalização força uma divisão internacional de trabalho, de caráter path dependent, que impõe, nos setores de tradables, a especialização de países de renda média em indústrias tradicionais, como as de processamento e produção de commodities, caracterizadas por rendimentos constantes ou decrescentes, e de países ricos em setores de alta tecnologia, intensivos em conhecimento e inovação, marcados por rendimentos crescentes, que oferecem vantagem competitiva permanente e lock-in aos países que primeiro alocaram seus fatores de produção a estes setores, sempre que as externalidades geradoras de rendimentos crescentes atuarem do lado da oferta e tiverem alcance geográfico limitado.

Conseqüentemente, os países de renda média tendem a ocupar o papel de ex- 
portadores de produtos marcados por rendimentos constantes ou decrescentes em sua produção, e importadores de produtos marcados por rendimentos crescentes em sua produção, que tendem a ser fabricados nos países ricos. Este padrão de divisão internacional de trabalho decorre da vantagem permanente, muitas vezes de caráter intersetorial, do primeiro entrante em indústrias com rendimentos crescentes, e impõe trajetórias de desenvolvimento divergentes para os países ricos e os países de renda média. O diferencial da taxa de crescimento da produtividade total de fatores entre os setores marcados por rendimentos crescentes e aqueles marcados por rendimentos constantes ou decrescentes faz com que a produtividade total de fatores cresça de forma mais acelerada nos países ricos, especializados em setores marcados por rendimentos crescentes. Isto implica uma tendência de elevação dos salários reais de países ricos em relação aos de países de renda média, e em uma conseqüente concentração internacional de renda.

O processo de globalização produz, assim, em um contexto de livre funcionamento dos mercados, um enriquecimento dos países ricos em relação aos de renda média. Apesar de viabilizar uma reorganização de fatores de produção que eleva o bem-estar social, estimula uma distribuição assimétrica do excedente. Esta conclusão tem importantes implicações normativas. A modificação desta dinâmica depende da ação dos Estados de países de renda média, que devem delinear estratégias nacionais de desenvolvimento capazes de modificar este padrão de divisão internacional de trabalho, rompendo seu caráter path dependent. Por este argumento, a globalização impõe um conflito distributivo entre os Estados-nação, porque materializa um ambiente de competição entre Estados de diferentes Estados-nação, no qual cada Estado procura conduzir sua economia a uma posição privilegiada na divisão internacional de trabalho, que possibilite a apropriação dos benefícios intertemporais oferecidos pelos setores caracterizados por rendimentos crescentes. Este processo é necessariamente competitivo porque a divisão internacional de trabalho induzida pela globalização impede que todos os países ocupem, simultaneamente, posições privilegiadas no comércio internacional. E são as estratégias nacionais de desenvolvimento que definem os vencedores e os perdedores deste processo. Elas podem catalisar uma realocação de capital e trabalho para setores marcados por rendimentos crescentes, modificando preços relativos de bens e fatores e reduzindo os custos de transação intrínsecos a esta dinâmica realocativa. Podem, também, dentro deste processo, fomentar externalidades geradoras de rendimentos crescentes que atuem do lado da oferta, de caráter setorial ou intersetorial, e alcance geográfico limitado, capazes de conferir vantagem permanente ao país em diversos setores, existentes ou ainda não inventados, marcados por rendimentos crescentes. Estas estratégias podem, ainda, obstruir este mesmo processo em outros países, "chutando a escada", como aponta Chang (2002), e conduzindo estes países a posições menos privilegiadas na divisão internacional de trabalho. 


\section{EM BUSCA DE UMA NOVA ESTRATÉGIA DE DESENVOLVIMENTO PARA O BRASIL}

As políticas ortodoxas adotadas no Brasil desde 1990, baseadas em um tripé de políticas liberalizantes coerentes com o Consenso de Washington - privatização, austeridade fiscal e liberalização comercial e financeira -, forçaram a adoção de uma política monetária restritiva, que resultou em significativa apreciação do câmbio real. Este processo foi intensificado, nos últimos anos, pela elevação da demanda externa de produtos primários, que contaminou a economia brasileira com a "doença holandesa”, como aponta Bresser-Pereira (2008). O modelo clássico de "doença holandesa", elaborado por Corden e Neary (1982), demonstra que um boom de exportações de produtos primários em um determinado país gera um efeito renda na economia que eleva o dispêndio doméstico e desloca, conseqüentemente, os fatores de produção tanto para o setor exportador de primários, quanto para os setores de non-tradables, causando um crowding-out dos demais setores de tradables, cuja demanda passa a ser atendida por importações. Este processo implica a apreciação do câmbio real, que tira a competitividade externa destes outros setores de tradables. Bresser-Pereira (2008) argumenta, ainda, que a "doença holandesa" se dá não só pela competitividade externa do setor primário, viabilizada por rendas ricardianas derivadas da riqueza natural brasileira, na linha da análise de Corden e Neary (1982), mas também pelo elevado leque salarial entre a mão-de-obra qualificada e não-qualificada no país, superior àquele observado em países ricos.

A política monetária restritiva e a "doença holandesa" induzem uma apreciação cambial que força a especialização da economia brasileira em setores tradicionais, marcados por rendimentos constantes ou decrescentes, que são impulsionados pelos recursos naturais e pela mão-de-obra barata do país. Os argumentos apresentados neste artigo sugerem ser possível a aceleração do crescimento econômico pela definição de uma nova estratégia nacional de desenvolvimento que envolva reformas institucionais e uma reorganização da política macroeconômica para fomentar o desenvolvimento de setores marcados por rendimentos crescentes de escala. Para tal deve garantir, através da política macroeconômica, uma estrutura de preços relativos de bens e fatores que torne competitivas, no mercado externo, as indústrias domésticas de tradables em setores marcados por rendimentos crescentes de escala, desde que os rendimentos crescentes derivem de externalidades de alcance geográfico limitado que atuam do lado da oferta. Exemplos importantes deste tipo de setor são o aeroespacial, o farmacêutico, o de biotecnologia e o de software e hardware de computadores. Este tipo de política pode compensar as vantagens competitivas que os rendimentos crescentes conferem aos primeiros entrantes destes setores no mercado internacional, e possibilitar o rompimento do caráter path dependent da divisão internacional de trabalho.

Se este processo se desse pela intervenção cambial direta, fomentaria uma expressiva elevação das reservas internacionais, e imporia um substancial custo financeiro ao Estado decorrente do diferencial das taxas de juro internacionais 
— que definem a rentabilidade das reservas internacionais - e domésticas - que definem o custo da dívida interna. Imporia, também, um desequilíbrio intertemporal que poderia ser prejudicial no longo prazo, já que a acumulação de reservas internacionais tem como contrapartida a acumulação de passivos externos dos outros países, que não poderia se manter indefinidamente. Como argumenta Bresser-Pereira (2008), a intervenção do Estado no câmbio poderia se dar de maneira indireta, através de uma política monetária mais expansionista, que limitasse o espaço de arbitragem entre as taxas de juro domésticas e externas, e da tributação do setor primário-exportador, indutor da "doença holandesa", de maneira a canalizar um subsídio cruzado aos setores marcados por rendimentos crescentes, semelhante àquele articulado no período do nacional-desenvolvimentismo, a partir de 1930, mas agora direcionando as estruturas produtivas domésticas ao mercado externo, e não ao mercado doméstico, como ocorreu naquele período. Este tipo de tributação mitigaria os impactos da "doença holandesa". Desvalorizaria o câmbio real, o que atenuaria as perdas do setor agrário-exportador, e aumentaria a competitividade externa das indústrias domésticas de setores marcados por rendimentos crescentes de escala. Geraria, também, uma receita tributária extra, que abriria espaço para a desoneração tributária destes setores, ampliando, assim, sua competitividade externa. Estas políticas, acompanhadas do controle de gastos públicos, reduziriam a relação dívida/PIB, e permitiriam uma retomada gradual do investimento privado, favorecendo a canalização de poupança e mão-de-obra para os setores marcados por rendimentos crescentes.

Estas políticas macroeconômicas devem ser acompanhadas de reformas institucionais que permitam que o processo realocativo de capital e mão-de-obra de setores tradicionais para setores de alta tecnologia, marcados por rendimentos crescentes, se dê de maneira pouco custosa. Nos últimos anos, a redefinição da lei das sociedades anônimas introduziu inovações institucionais que resguardaram direitos de acionistas minoritários, mitigando os custos da assimetria informacional entre investidores e tomadores. A auto-regulação da Bolsa de Valores de São Paulo criou mecanismos ainda mais robustos para proteger os acionistas minoritários, através da criação do Novo Mercado. Estes fatores, assim como a definição de uma lei para reger o funcionamento dos fundos de investimentos em participações — ou fundos de private equity —, e de uma nova lei de falências, de caráter prócredor, que também ataca os custos derivados da assimetria informacional entre investidores e tomadores, criaram condições para uma canalização menos custosa de poupança para investimentos de risco, normalmente relacionados a setores de alta tecnologia, marcados por rendimentos crescentes, intensivos em inovação. Contudo, não houve, durante este período, o mesmo progresso institucional para garantir uma realocação pouco custosa de mão-de-obra para estes setores. As leis trabalhistas impõem forte rigidez ao mercado de trabalho, dificultando a mobilidade da mão-de-obra. O baixo nível educacional do trabalhador brasileiro limita seu potencial de qualificação, e torna extremamente custosa sua realocação. Não houve, também, ação ativa do Estado brasileiro para fomentar externalidades geradoras de rendimentos crescentes, que atuem do lado da oferta e que tenham 
alcance geográfico limitado, como no exemplo do pólo tecnológico de São José dos Campos.

A redefinição de uma estratégia de desenvolvimento para o Brasil passa, portanto, pelo entendimento do seu impacto sobre a divisão internacional de trabalho, que determina, em grande parte, o potencial de crescimento do padrão de vida no país. Se este entendimento pode permitir, por um lado, uma avaliação mais profunda das políticas públicas e instituições existentes no país, pode nortear, por outro lado, o esforço de construção de uma nova estratégia de desenvolvimento, capaz de catalisar um processo realocativo de bens e fatores que impulsione o crescimento econômico e eleve o padrão de vida no país.

\section{REFERÊNCIAS BIBLIOGRÁFICAS}

ARTHUR, W. B. (1996) "Increasing Returns and the Two Worlds of Business". Harvard Business Review, July-August 1996.

BRESSER-PEREIRA, L.C. (2007) "Macroeconomia da Estagnação e o Novo Desenvolvimentismo", em Bresser-Pereira, org. (2007) .Nação, Câmbio e Desenvolvimento. Rio de Janeiro, Editora da Fundação Getulio Vargas.

BRESSER-PEREIRA, L.C. (2008) “The Dutch disease and its neutralization: a Ricardian approach". Revista de Economia Política 28 (1), janeiro 2008: 47-71.

CHANG, H. J. (2002) Chutando a Escada - A Estratégia do Desenvolvimento em Perspectiva Histórica. São Paulo: Fundação Editora da UNESP.

HOFF, K. (2000) "Beyond Rosenstein-Rodan: The Modern Theory of Coordination Problems in Development". Proceedings of the Annual World Bank Conference on Development Economics, 2000.

ROMER, D. (1996) Advanced Macroeconomics. New York: McGraw Hill.

ROMER, P. M. (1986) “Increasing Returns and Long Run Growth”. Journal of Political Economy 94 (October): 1002-1037.

ROMER, P. M. (1990) “Endogenous Technological Change”. Journal of Political Economy 98 (October), S71-S102. 